\title{
A TEORIA DO ADIMPLEMENTO SUBSTANCIAL NA ALIENAÇÃO FIDUCIÁRIA DE IMÓVEL EXTRAJUDICIAL
}

\author{
Amanda Krul Gallego*
}

\section{RESUMO}

A alienação fiduciária de imóvel, instituída pela Lei 9.514/97, prevê o procedimento de consolidação da propriedade do bem alienado em caso de inadimplemento do devedor, sendo tal procedimento totalmente extrajudicial. Ocorre que, a inexistência de limite ao direito do credor fiduciário na resolução do vínculo, ocasiona em abusos e onerosidade excessiva contra o devedor fiduciante. Ante esta realidade, e com base nos princípios gerais do direito, a aplicação da teoria do adimplemento substancial se mostra ideal. Entretanto, por não possuir previsão legal, sendo sua aplicação condicionada à interpretação subjetiva do magistrado, o que temos, em consequência, é uma grande insegurança jurídica. Para a solução deste problema, portanto, necessário se faz a normatização do adimplemento substancial na Lei 9.514/97, conferindo-lhe razoabilidade. Em que pese o desenvolvimento do presente trabalho, ressalta-se que foi utilizada a metodologia de pesquisa bibliográfica e descritiva, e a conclusão deu-se a partir do método dedutivo. O objetivo, aqui, é demonstrar a problemática existente em nosso ordenamento e propor uma solução plausível, para que esteja protegido veementemente, o direito social à moradia, previsto no art. $6^{\circ}$ da Constituição Federal.

Palavras-chave: Adimplemento substancial. Alienação fiduciária de imóvel.

\section{THE THEORY OF SUBSTANTIAL PERFORMANCE IN THE FIDUCIARY SALE OF EXTRAJUDICIAL PROPERTY}

\section{ABSTRACT}

The fiduciary alienation of property, instituted by Law 9.514/97, provides for the procedure for consolidating ownership of the alienated asset in the event of default by the debtor, which is a totally out-of-court procedure. It so happens that the absence of a limit on the right of the fiduciary creditor in the resolution of the bond, causes abuses and excessive burdens on the fiduciary debtor. In view of this reality, and based on the general principles of law, the application of the theory of substantial performance is ideal. However, as it does not have a legal provision, its application being conditioned to the subjective interpretation of the magistrate, what we have, consequently, is a great legal uncertainty. Therefore, to solve this problem, it is necessary to standardize the substantial performance in Law 9.514/97, giving it reasona-

* Graduanda do Curso de Direito na Universidade Metodista de São Paulo. 
bleness. Despite the development of the present work, it is emphasized that the methodology of bibliographic and descriptive research was used, and the conclusion was based on the deductive method. The objective here is to demonstrate the existing problem in our organization and propose a plausible solution, so that the social right to housing, provided for in art. 6th of the Federal Constitution.

Keywords: Substantial performance. Fiduciary sale of property.

\section{INTRODUÇÃO}

O presente trabalho consiste no estudo aprofundado da causa e possível solução para a insegurança jurídica existente em nosso ordenamento, ao tratarmos da teoria do adimplemento substancial na alienação fiduciária de imóvel.

A teoria do adimplemento substancial é uma construção doutrinária e jurisprudencial que, embora não possua previsão legal, ganhou espaço em nosso ordenamento jurídico, sendo fundamentada nos princípios da boa-fé contratual e da função social do contrato.

Referida teoria, busca limitar o direito potestativo do credor, previsto no artigo 475 do Código Civil, e entende que, em caso de inadimplemento sobre montante insignificante da obrigação total, não é razoável a resolução do contrato, bastando, para tanto, a execução da dívida por meios menos gravosos ao devedor de boa-fé, com a possibilidade, ainda, de perdas e danos.

A alienação fiduciária de imóvel, por sua vez, consiste na transmissão da propriedade resolúvel do imóvel em favor do credor fiduciário, em troca de crédito, a ser pago em prestações pelo devedor que, ao final da obrigação, será restituído do domínio do imóvel deixado em garantia.

Referido instituto, regulamentado pela Lei 9.514, de 20 de novembro de 1997, pertence à classe dos direitos reais e visa fomentar a economia nacional, incentivando a liberação de crédito por parte das instituições financeiras, por meio da segurança a estas garantida, dada a praticidade na recuperação do crédito em caso de inadimplemento do devedor fiduciante.

Em caso de inadimplemento, portanto, o credor fiduciário poderá, de forma administrativa, consolidar a propriedade do imóvel deixado em garantia, e aliená-lo em leilão extrajudicial, nos termos da lei específica.

No entanto, tal procedimento enseja abusos e enriquecimento ilícito por parte das instituições financeiras que, com extremo rigor, exercem seu direito à resolução do vínculo com o devedor fiduciante em decorrência de dívidas irrisórias, gerando grandes injustiças e desproporcionalidades em face do devedor de boa-fé, principalmente pelo fato de que, aqui, tratamos de um bem imóvel, de modo que a problemática está, na maioria dos casos concretos, diretamente ligada ao direito de moradia, vide artigo $6^{\circ}$ da Constituição Federal.

Esta situação, vivida por muitos brasileiros, culminou em grande número de demandas judiciais, as quais buscam a reversão da venda administrativa do imóvel. O fundamento para tais demandas está exatamente na teoria do adimplemento substancial que, conforme mencionado anteriormente, está alicerçada nos 
princípios da boa-fé e da função social do contrato e, ainda, está implicitamente ligada a preceitos constitucionais.

Ocorre que, embora a teoria do adimplemento substancial seja a perfeita resposta jurídica aos abusos cometidos pelos credores fiduciários, esta não possui força normativa, e sua aplicação está sujeita a interpretação subjetiva do magistrado.

Esta incerteza, portanto, gera grande insegurança jurídica, ao ponto em que situações análogas podem ter desfechos diferentes a depender do intérprete da lide. Veja que, o abuso legitimado pela Lei 9.514/97, existe. Mas a solução para este problema, embora também exista, não é garantida.

Nesta questão é que reside a hipótese deste trabalho: quais consequências práticas decorrem da insegurança jurídica na aplicação do adimplemento substancial na alienação fiduciária de imóvel? A normatização do adimplemento substancial solucionaria o problema? Quais critérios deveriam ser previstos para sua aplicação?

Ademais, a hipótese será desenvolvida a partir da metodologia bibliográfica e descritiva, reunindo materiais sobre o tema para sua exata compreensão. Além disso, por meio do método dedutivo, será elaborada conclusão lógica a respeito do assunto.

O objetivo desta pesquisa é demonstrar o quanto a teoria do adimplemento substancial carece de previsão legal, principalmente quando analisada da ótica da alienação fiduciária de imóvel, que está prevista em legislação específica e que afasta o procedimento executório da apreciação do Poder Judiciário. Busca-se, em suma, (I) analisar a relação entre adimplemento substancial e alienação fiduciária de imóvel; (II) identificar o problema entre estes e (III) sugerir solução efetiva ao problema, qual seja a normatização do adimplemento substancial na Lei 9.514/97.

\section{SISTEMA JURÍDICO BRASILEIRO}

É cediço que somos um país com origens romano-germânicas, isto é, adotamos desde os primórdios, o civil law como sistema jurídico. Tal afirmativa, em suma, significa dizer que no Brasil, a lei é e sempre foi a principal fonte do Direito, de modo que visa garantir a segurança jurídica.

Entretanto, o conceito original de civil law, se destoa do que conhecemos hoje, haja vista os questionamentos e reflexões levantados num momento pós-segunda guerra mundial (1939-1945).

Em suma, todos os países que adotaram o civil law e a dogmática positivista como sistema, passaram por grande reformulação de ideias, questionando todo o ordenamento e retomando a valorização da filosofia do direito, que outrora esteve esquecida, haja vista o extremo e estrito cumprimento do que estava na lei.

O primeiro ponto levantado naquele momento pós-segunda guerra, dizia respeito à efetividade da justiça, isto é, a justiça e a lei andavam realmente juntas?

Conforme texto dirigido aos estudantes da Universidade de Heidelberg, em 1945, 
povo e os juristas contra as leis mais arbitrárias, mais cruéis e mais criminosas. (MONCADA, 1974, p. 415 - 418).

Veja que, os filósofos e juristas, então, passaram a criticar o estrito e cego cumprimento das leis impostas, que per si não garantiriam justiça; era necessário o juízo de valor das normas aplicáveis: "a aquiescência às leis evidentemente não é suficiente para a justiça; a aquiescência plena provocará injustiça muito séria se suas regras forem injustas". (DWORKIN, 2007, p. VII).

Portanto, todos os sistemas que encaravam a lei como fonte propulsora do direito, foram readaptados para que houvesse, ativamente, o anseio de justiça a ser legitimado pela previsão de normas valorativas presentes numa Constituição rígida.

Veja que, anteriormente a este momento, já existiam as Constituições Federais de cada nação optante, mas que objetivavam muito mais delimitar os poderes políticos, do que garantir a efetividade da justiça.

Por este motivo é que os autores interpretam este momento (pós-segunda guerra) como o marco do neoconstitucionalismo, isto é, muito mais do que um Estado constitucional, originou-se um Estado neoconstitucional, onde existia a preocupação para com os direitos fundamentais, e não mais a separação entre moral e direito.

Desta forma, como em todos os países que adotavam o sistema romano-germânico em seu ordenamento, com o Brasil não foi diferente, de modo que a materialização do neoconstitucionalismo foi a Constituição Federal de 1988, que nos trouxe grande carga valorativa e principiológica, com os objetivos de justiça, liberdade e solidariedade, vide art. $3^{\circ}$, inc. I.

A Constituição, neste ponto, deixou de ter caráter abstrato e longínquo, para incorporar o sistema jurídico propriamente dito, sendo a Lei Maior do Estado Democrático de Direito, com efeito vinculante em todos os âmbitos jurídicos.

Ainda, resta esclarecer que, quando falamos em Constituição Federal "realizadora de direitos" e com efeito vinculante em todo o ordenamento, afirmamos, também, que a dicotomia entre Direito Público e Privado já não mais existe, de forma que os princípios constitucionais devem ser aplicados inclusive nas relações privadas:

\footnotetext{
A maturação dos estudos acerca da CF, de 1988, e suas potencialidades, bem como a superação do entendimento, segundo o qual Direito Público e Privado seriam opostos e incomunicáveis, levou à gradual aplicação das normas constitucionais às relações privadas. Vive-se, então, uma fase na qual se admite amplamente a aplicação direta das normas constitucionais. (TEPEDINO, 2011, p. 100).
}

Tal publicização do direito privado, portanto, culminou no Código Civil de 2002, que se distanciou "do tecnicismo institucional advindo da experiência do direito romano, procurando, em vez de valorizar formalidades, reconhecer a participação dos valores éticos em todo o direito privado" (TARTUCE, 2005, p. 43), nos apresentando, assim, um sistema unitário: 
O direito é um sistema lógico de normas, valores e princípios que regem a vida social, que interagem entre si de tal sorte que propicie segurança - em sentido lato - para os homens e mulheres que compõem uma sociedade. Assim sendo, momentos existem em que esses ramos do direito se veem tutelando quase que os mesmos direitos. (TARTUCE, 2005, p. 63).

Esta publicização do direito, inclusive, gerou o que os doutrinadores chamam de direito civil-constitucional, ramo o qual "realça a necessária releitura do Código Civil e das leis especiais à luz da Constituição, redefinindo as categorias jurídicas civilistas a partir dos fundamentos principiológicos constitucionais [...]" (GONÇALVES, 2015, p. 45), de modo que se impôs ao direito privado a primazia da coletividade sobre o individualismo, a ser fiscalizada pelo Estado:

O Direito Civil, assim como os outros ramos do chamado direito privado, assistiu a uma profunda intervenção por parte do Estado, na tentativa de evitar que a exasperação da ideologia individualista - em vez de gerar o que se imaginara no século anterior, ou seja, a riqueza das nações e das pessoas - continuasse a acirrar as desigualdades, com a formação de novos miseráveis, tornando inviável até mesmo o regime de mercado, essencial ao capitalismo. (TEPEDINO, 2019, p. 28).

Veja que o Direito, a partir deste cenário, ganha nova estrutura, de modo que, hierarquicamente, não se limita mais ao texto legal, mas sim à Constituição Federal, que incide em todos os ramos do direito. Contudo, como consequência disso, e tendo em vista que a Constituição possui essência principiológica e valorativa, $\mathrm{o}$ que temos é uma amplitude do campo interpretativo do magistrado:

[...] o neoconstitucionalismo implica a possibilidade de se proceder a uma leitura moral da Constituição no sentido de uma interpretação criativa ou construtiva que não apenas revela novos direitos, mas principalmente, alarga o campo de cabimento e proteção daqueles já existentes. (ROSSI e PAMPLONA, 2013, p. 21).

Esta mudança de postura do Judiciário, que evoluiu o papel da magistratura ao ponto em que lhe deu nova margem interpretativa, gerou o fenômeno jurídico chamado "ativismo judicial", conceituado e defendido por Luís Roberto Barroso:

O ativismo judicial, por sua vez, expressa uma postura do intérprete, um modo proativo e expansivo de interpretar a Constituição, potencializando o sentido e alcance de suas normas, para ir além do legislador ordinário. Trata-se de um mecanismo para contornar, bypassar o processo político majoritário quando ele tenha se mostrado inerte, emperrado ou incapaz de produzir consenso. (BARROSO, 2009, p. 30).

A compreensão de todo este cenário, portanto, é importante porquê a recepção da teoria do adimplemento substancial no Brasil só foi possível devido a estas modificações estruturais e hermenêuticas em nosso ordenamento. A publicização 
do direito deu azo à interpretação principiológica do Código Civil, e o ativismo jurídico possibilitou que os magistrados proferissem sentenças com fundamentos extralegais, isto é, não baseados na lei, sem previsão normativa.

Entretanto, o mesmo fenômeno que possibilitou a recepção do adimplemento substancial em nosso país, é aquele que, atualmente empregado de forma corriqueira, e não excepcional, gera grande insegurança jurídica em nosso ordenamento, inclusive, no que tange à aplicação da própria teoria da substantial performance.

Em outras palavras, o ativismo jurídico empregado de forma exacerbada, como ocorre no Brasil, gera o oposto do que se objetiva. Veja que, apesar de termos no Brasil, como fonte não formal do direito, a jurisprudência, somos ainda um sistema romano-germânico, não dispondo, portanto, de mecanismos suficientes que pacifiquem as interpretações e decisões proferidas em caráter ativista, o que gera a perda de capital jurídico e a consequente incerteza do direito:

Em um sistema romano-germânico, como o brasileiro, em que a ativi-
dade adjudicatória estava historicamente vinculada à aplicação da lei,
era natural que não houvesse muitos instrumentos de uniformização
jurisprudencial, pois estes não eram necessários, bastava a lei. Mas com
o aumento do ativismo judicial e a diminuição do papel uniformizador
da lei, os magistrados brasileiros, acostumados a considerar apenas a lei
como parâmetro, passaram cada vez mais a decidir cada caso livremen-
te, sem considerar a experiência prévia de seus pares (jurisprudência),
o que significa que, na resolução de disputas, regras jurídicas não são
criadas e o estoque de capital jurídico deprecia-se sem ser reposto, au-
mentando a insegurança jurídica. É importante frisar que é a ausência
de uniformização de jurisprudência e não o ativismo judicial per si que
reduz o estoque de capital jurídico, pois, na definição aqui adotada, não
importa a origem das regras jurídicas, se legislativa ou judicial, já que
não se trata de uma questão de legitimidade, mas de previsibilidade e
eficácia das regras. (GICO JUNIOR, 2015, p. 483).

Conforme explica Luís Roberto Barroso, “decisões ativistas devem ser eventuais, em momentos históricos determinados. Mas não há democracia sólida sem atividade política intensa e saudável, nem tampouco sem Congresso atuante e investido de credibilidade". (2009, p. 24).

O que se vê, no entanto, é a imobilização do Legislativo quanto a questões importantíssimas carentes de normatização, e o livre convencimento motivado dos magistrados sendo empregado como legitimador da "autopoiése do direito". (STRECK, 2018, p. 282).

Veja que a questão da insegurança jurídica em decorrência do ativismo judicial, é exatamente o que ocorre na aplicação do adimplemento substancial na alienação fiduciária de imóvel: as decisões judiciais tornaram-se subjetivas e discricionárias, de modo que, o devedor fiduciante de boa-fé, fica à mercê da interpretação do magistrado, que pode ou não aplicar referida teoria no caso concreto. $\mathrm{O}$ problema apenas será solucionado mediante a mobilização do legislativo, no que tange à normatização do adimplemento substancial. Em caso contrário, continuará vívido o problema. 
Ademais, é essencial compreender o ativismo judicial como solução para concretização da justiça em meio às lacunas legais, mas jamais como substituto do Poder Legislativo, que permanece responsável pela criação de leis em nome dos interesses do povo, vide art. $1^{\circ}$, parágrafo único, $\mathrm{CF} / 88$. Se nosso sistema jurídico não prevê mecanismos os quais garantem a pacificidade jurisprudencial nas corriqueiras matérias controvertidas (afim de garantir a segurança jurídica) em detrimento da tradição romano-germânica, é imprescindível que o Legislativo acompanhe o dinamismo enfrentado pelo Judiciário e normatize direitos majoritariamente reconhecidos, para que seja alcançada a segurança jurídica e para que o ativismo não se desvincule de seu desígnio original.

\section{TEORIA DO ADIMPLEMENTO SUBSTANCIAL}

A teoria do adimplemento substancial consiste na ideia de razoabilidade e temperança nas relações contratuais. (FERREIRA, 2015).

Em outras palavras, nos contratos bilaterais, é cediço que existem obrigações estipuladas para ambos os contratantes, de modo que o vínculo se extingue mediante o cumprimento das prestações convencionadas. Contudo, nem sempre as obrigações são adimplidas em sua totalidade, sendo que nestes casos, a regra geral é de que o contrato seja rescindido.

No entanto, desta máxima jurídica é que se originou a teoria do adimplemento substancial que, de forma simplista, corresponde a uma exceção à regra geral de extinção dos contratos inadimplidos, a qual entende não ser razoável a resolução do contrato em detrimento de inadimplemento mínimo por parte do devedor.

Frisa-se, ainda, que é incontroverso entre os pesquisadores que a substantial performance originou-se na Inglaterra, que desde os primórdios adotou um sistema jurídico consuetudinário, o qual possibilitou a inversão do ponto de vista do julgador mediante flagrantes injustiças ocorridas pelo estrito cumprimento dos contratos e costumes já consolidados, sendo que, foi a partir do desenvolvimento da teoria do adimplemento substancial na Inglaterra, que outros países passaram a recepcioná-la em seus respectivos ordenamentos, como a Alemanha (BGB, §325 (5)), Itália (CC, art. 1455), e Portugal (CC, art. 802 (2)).

Já no Brasil, o adimplemento substancial não possui previsão legal. Desta feita, mediante o ativismo exercido pelo Judiciário - que possibilita ao intérprete a criação de direitos em consonância com a Constituição Federal - o adimplemento substancial passou a ser gradativamente discutido e aplicado nos casos concretos, havendo atualmente, grande (não absoluta) aceitação no ordenamento jurídico pátrio.

\subsection{RECEPÇÃO DO ADIMPLEMENTO SUBSTANCIAL NO BRASIL}

Grosso modo, o adimplemento substancial consiste na limitação ao direito do credor, previsto do art. 475, C.C., quanto à resolução do contrato em decorrência de inadimplemento. Segundo a teoria, o inadimplemento de valor insignificante não gera a quebra do vínculo jurídico, e está fundamentada nos princípios da boa-fé e da função social do contrato. 
Referido instituto foi importado ao nosso país pelas lições de Clóvis Veríssimo do Couto e Silva, advogado e jurista, que atuou como professor na Faculdade de Direito da Universidade Federal do Rio Grande do Sul, e também como membro da comissão elaborada do anteprojeto do Código Civil de 2002.

Em 1979, o autor, pela primeira vez, tratou do adimplemento substancial ao participar da I Jornada Luso-Brasileira de Direito Civil, promovida pelo Instituto dos Advogados do Rio Grande do Sul. Deste evento resultou o livro "Estudos de direito civil brasileiro e português: I Jornada luso-brasileira de direito civil", editado pela Revista dos Tribunais, em 1980, marcando assim, a evolução do direito civil brasileiro, mediante a grande repercussão gerada.

Nesta obra, Couto e Silva apresenta ao Brasil a teoria do adimplemento substancial, definindo-o como: "[...] um adimplemento tão próximo ao resultado final, que, tendo-se em vista a conduta das partes, exclui-se o direito de resolução, permitindo tão somente o pedido de indenização". (1980, p. 56).

O autor utilizou tão somente o princípio da boa-fé para conceituação da teoria do adimplemento substancial, sendo que apenas este bastaria para que não se entendesse justa a rescisão de contrato em decorrência de inadimplemento insignificante:

O princípio da boa-fé objetiva aí atua de forma a proteger o devedor frente a um credor malicioso, inflexível [...], como causa de limitação do exercício de um poder jurídico, no caso, do direito formativo de resolução, do qual é titular o credor de obrigação não cumprida. (BECKER, 1993, p. 70).

Ainda, mister se faz ressaltar que, a teoria do adimplemento substancial não visa gerar prejuízos ao credor. O que foi pactuado entre as partes, deverá ser cumprido. O que se discute, aqui, é a resolução do contrato.

A fim de elucidar a questão, exemplificamos: imagine que " $A$ " contratou " $B$ " para que fosse realizada a pintura de seu apartamento (sala e dois dormitórios) no prazo de uma semana. A título de remuneração, "A" pagaria a quantia de um mil reais a " $\mathrm{B}$ " após a finalização do serviço. No entanto, após pintar a sala e um dos dormitórios, " $\mathrm{B}$ " adoeceu, ficando impossibilitado de completar o serviço e, assim, não cumprindo com sua obrigação no prazo firmado. " $\mathrm{A}$ ", que contava com a pintura do apartamento para concluir sua mudança, sentiu-se lesado, e negou-se a pagar pelo serviço contratado, alegando, ainda, que contrataria outro profissional para finalização do serviço. Veja que " $A$ " rescindiu o contrato firmado; no entanto, tal conduta se mostra injusta, visto que "B" de boa-fé, inadimpliu apenas parte ínfima da obrigação, sendo razoável sua remuneração proporcional. Ainda, se " $A$ " sentiu-se lesado, é justo também que seja analisada a possibilidade de indenização. Mas, nota-se, a quebra de contrato, neste caso, não seria justa, ainda que legitimada pela regra geral do Código Civil.

Portanto, veja que, a teoria do adimplemento substancial não afasta do credor seu direito, mediante a isenção do devedor quanto ao cumprimento da obrigação 
faltante, mas sim, afasta do credor a possibilidade de abuso do direito, bem como do enriquecimento ilícito.

Ademais, apesar da doutrina de Clóvis V. do Couto e Silva, o adimplemento substancial não foi recepcionado em nosso ordenamento de forma instantânea. $\mathrm{O}$ primeiro acórdão que tratou da teoria em foco, foi proferido apenas após a promulgação da Constituição Federal de 1988, pelo relator e ministro do Superior Tribunal de Justiça - e ex-aluno de Couto e Silva - Ruy Rosado de Aguiar Junior.

Referido acórdão foi proferido em 11 de dezembro de 1995, e o caso pode ser sintetizado da seguinte forma: a) a lide versava sobre contrato de seguro; b) os segurados deixaram de adimplir a última parcela do "prêmio"; c) no mesmo dia do inadimplemento, ocorreu o sinistro do veículo objeto do contrato; d) a seguradora negou-se a cobrir o sinistro, em decorrência do inadimplemento da última parcela; e) mediante ação de cobrança e posterior recurso, o Tribunal de Justiça do Mato Grosso entendeu estar a seguradora correta, nada devendo aos segurados.

Assim, chegando o caso ao Superior Tribunal de Justiça, o relator Ruy Rosado decidiu de forma favorável aos segurados, de modo que, dentre outros fundamentos, tratou do cumprimento substancial da obrigação:

A falta de pagamento de uma prestação, considerando o valor total do negócio, não autorizava a seguradora a resolver o contrato, pois a segurada havia cumprido substancialmente o contrato. Ora, havendo o adimplemento substancial, descabe a resolução. (Recurso Especial 76.362/MT, $4^{\circ}$ Turma de Direito Privado, STJ. Relator: Ruy Rosado de Aguiar Jr. Proferido em 11/12/1995).

É fato que, apesar de aplicada por Ruy Rosado, a teoria do adimplemento substancial só passou a ser efetivamente reconhecida após a promulgação do Código Civil de 2002 por dois principais motivos: o primeiro concernente à normatização do princípio da boa-fé e da função social do contrato; e o segundo, concernente aos enunciados aprovados na IV e VII Jornada de Direito Civil, coordenadas, inclusive, pelo próprio ministro.

As Jornadas de Direito Civil passaram a ser promovidas pelo Conselho da Justiça Federal em 2002, e reuniam "professores, magistrados e membros das diferentes carreiras jurídicas para, após estudar o texto do Código Civil (em alguns casos, aplicarem-no) trocar informações e sugestões para um aperfeiçoamento da compreensão do texto legal" (FRADERA, 2019).

Tais enunciados referentes ao instituto do adimplemento substancial, esclareceram:

O adimplemento substancial decorre dos princípios gerais contratuais, de modo a fazer preponderar a função social do contrato e o princípio da boa-fé objetiva, balizando a aplicação do art. 475. (Enunciado no 361, IV Jornada de Direito Civil/CJF). 
Para a caracterização do adimplemento substancial [...] levam-se em conta tanto aspectos quantitativos quanto qualitativos. (Enunciado $\mathrm{n}^{\circ}$ 586, VII Jornada de Direito Civil/ CJF).

Portanto, é evidente que o adimplemento substancial faz parte do ordenamento jurídico brasileiro, de modo que, a partir do ativismo judicial é que foi possível sua recepção.

Atualmente, existem diversas abordagens doutrinárias referentes à teoria do adimplemento substancial. A exemplo disso, citamos Bussatta, que discorre sobre a excepcionalidade com que deve ser tratada a resolução dos contratos, prevista no art. 475, do Código Civil, e adentra ao instituto do adimplemento substancial de forma clara e objetiva:

A resolução é remédio grave por romper com o vínculo jurídico, desfazendo o contrato e todos os seus efeitos, [...]. Assim, tal remédio somente deve ser usado em situações de gravidade, não estando de acordo com a boa-fé o seu uso em situação em que o inadimplemento é de escassa importância. Funciona a resolução como ratio extrema [...] Só se pode pensar na resolução do contrato quando o descumprimento é sério, lesivo aos interesses da parte não inadimplente. Tal descumprimento deve retirar o sinalagma funcional do contrato, afastando sua função econômico-social. (BUSSATTA, 2007, p. 93).

Além disso, a autora Mariana R. Siqueira, ao tratar do instituto, explica que, quando falamos na boa-fé como fundamento do adimplemento substancial, estamos falando da função de controle do exercício de direitos subjetivos deste princípio, que culmina na invalidade de "atos que, embora estrutural e formalmente praticados dentro dos limites legais, estão em desconformidade com o ordenamento ou com a finalidade que o negócio pretende atingir". (SIQUEIRA, 2019, p. 313).

No entanto, embora defendam muitos autores que o adimplemento substancial faz parte do capital jurídico brasileiro em decorrência de construções doutrinárias e jurisprudenciais, temos que tal afirmação é equivocada no que tange às jurisprudências. Com a devida vênia, apesar deste instituto ser reconhecido nas doutrinas e nos enunciados da Jornada de Direito Civil, não há jurisprudência pacificada a seu respeito. O que temos, na realidade, são interpretações diversas em relação ao tema.

Elucidamos ainda, que, quando tratamos do adimplemento substancial em sentido amplo - pela ótica do direito obrigacional no geral - as divergências estão relacionadas aos critérios quantitativos e qualitativos. No entanto, quando tratamos da teoria em sentido estrito, referente aos seus reflexos na alienação fiduciária de imóvel. As divergências estão relacionadas aos critérios de aplicabilidade do instituto nos casos concretos, o que gera grande insegurança jurídica, resultando em decisões injustas que legitimam o abuso de direito por parte do credor fiduciário, de modo que, em casos análogos, o adimplemento substancial pode ser aplicado por um magistrado, e negado por outro. 
Em síntese, juízes ativistas, que buscam a efetiva justiça em suas decisões, recepcionam a teoria do adimplemento substancial em seus julgados. No entanto, juízes que possuem uma postura de autocontenção - antítese do ativismo judicial - se restringem ao estrito cumprimento do texto legal.

\section{DA ALIENAÇÃO FIDUCIÁRIA DE IMÓVEL}

Em 1997, o Brasil era governado por Fernando Henrique Cardoso, eleito nas eleições de 1993, e que implantava no país a política neoliberal.

Buscar o crescimento econômico por meio da não intervenção estatal, privatizando empresas e estimulando o mercado privado, é uma das principais características do neoliberalismo, sendo que, foi neste contexto político que a Lei 9.514/97 fora promulgada, visando, sobretudo, fomentar a liberação de crédito das instituições bancárias ao consumidor, uma vez que, desburocratizando a consolidação dos bens deixados em garantia na contratação do crédito, aumentaria, automaticamente, a circulação de bens e consumo.

Os especialistas da área financeira muito falam sobre a crise que pairava sobre a economia brasileira na década de 1990, haja vista que, em decorrência dos prejuízos causados pela inefetividade da hipoteca, tal garantia já não supria a necessidade do mercado, sendo necessário um instrumento capaz de impulsionar a economia.

Portanto, com a promulgação da Lei 9.514/97, que instituiu o Sistema Financeiro Imobiliário bem como a alienação fiduciária de bem imóvel como garantia, as instituições bancárias, com mais segurança, alavancaram a liberação de crédito imobiliário, resultando na maior circulação de bens e serviços, gerando empregos, aumentando a construção civil e possibilitando a aquisição da "casa" própria, estando a lei, portanto, alicerçada nos direitos sociais previstos na Constituição Federal de 1988.

Para grande parte da doutrina, a lei representou algo positivo em nosso país, levando em consideração os desdobramentos citados no parágrafo anterior. No entanto, há os opositores a este entendimento, como é o caso de Adroaldo Furtado Fabrício, que compreende a alienação fiduciária de imóvel como "mais um fruto dileto do neoliberalismo econômico em moda" (2000, p. 355-356), pois, segundo o autor, o único objetivo desta lei era a lucratividade de construtoras e instituições bancárias, prevalecendo assim, os interesses econômicos sobre os sociais, o que estaria em sentido oposto ao que dispõe a Carta Magna.

Neste trabalho, entendemos que há verdade em ambos os posicionamentos, tanto contrários, quanto favoráveis à referida lei. Veja que, de fato, a Constituição Federal prevê princípios, objetivos e garantias que convalescem com o instituto, como é o exemplo do artigo $3^{\circ}$, inc. II, que trata do desenvolvimento nacional como um dos objetivos do Estado; o artigo $6^{\circ}$, caput, que afirma serem direitos sociais o trabalho e a moradia; e o artigo 170, inc. VIII, que dispõe ser princípio da ordem econômica, a busca do pleno emprego.

No entanto, em contrapartida, temos também os princípios da dignidade da pessoa humana (art. $1^{\circ}$, inc. III, CF); a garantia de uma sociedade justa (art. $3^{\circ}$, inc. I, 
CF); o princípio da função social da propriedade (art. $5^{\circ}$, inc. XXII e art. 170, inc. III, $\mathrm{CF}$ ); e a garantia da justiça social como alicerce da ordem econômica (art. 170, caput). Com a análise de tais dispositivos constitucionais, concluímos, portanto, que, em primeiro lugar, os direitos sociais prevalecem sobre os econômicos, de modo que a ordem econômica está subordinada à justiça social conforme artigo já citado. Em segunda análise, temos que não é razoável a crença na possibilidade de garantia de trabalho, moradia e dignidade da pessoa humana, sem o desenvolvimento nacional econômico. Portanto, podemos concluir que, apesar de implícito, o princípio essencial nesta questão é o equilíbrio entre tais interesses, em tese, antagônicos.

A lei que regulamenta a alienação fiduciária de imóvel é importantíssima para a economia nacional, de fato. No entanto, não podemos fechar os olhos para o desequilíbrio entre fiduciário e fiduciante, que resulta em desproporcionalidades e injustiças, conforme trataremos a seguir.

Ademais, uma vez superado o contexto histórico do qual emergiu a lei em questão, bem como compreendido qual o interesse dos legisladores ao promulgá-la, seguiremos para o estudo do que de fato consiste na alienação fiduciária de imóvel, e quais são suas consequências fáticas e jurídicas.

\subsection{Afinal, em Que consiste a Alienação Fiduciária de Bem Imóvel?}

A alienação fiduciária de bem imóvel refere-se a uma garantia de direito real, e está prevista em legislação específica (Lei 9.514/97), com o seguinte texto:

Art. 22. A alienação fiduciária regulada por esta Lei é o negócio jurídico pelo qual o devedor, ou fiduciante, com o escopo de garantia, contrata a transferência ao credor, ou fiduciário, da propriedade resolúvel de coisa imóvel.

$[\ldots]$

Art. 23. Constitui-se a propriedade fiduciária de coisa imóvel mediante registro, no competente Registro de Imóveis, do contrato que lhe serve de título.

Parágrafo único. Com a constituição da propriedade fiduciária, dá-se o desdobramento da posse, tornando-se o fiduciante possuidor direto e o fiduciário possuidor indireto da coisa imóvel. (BRASIL, Lei 9.514, 1997).

Assim, como bem explica Carlos R. Gonçalves (2020, p. 446),

Na propriedade fiduciária dá-se a transferência do domínio do bem [...] ao credor, denominado fiduciário, em garantia do pagamento, permanecendo o devedor (fiduciante) com a posse direta da coisa. O domínio e a posse indireta passam ao credor, em garantia. Não se dá a tradição real, mas sim ficta [...]. O domínio do credor é resolúvel, pois resolve-se automaticamente em favor do devedor alienante [...]. 
Veja que, com esta lei, as instituições financeiras em muito se beneficiaram; tornou-se simples a resolução do contrato em decorrência de inadimplemento, uma vez já estar o bem incorporado no patrimônio do credor, diferentemente do que ocorre na hipoteca: "A hipoteca é direito real de garantia que recai sobre coisa alheia [...]. O credor (fiduciário) possui um direito de garantia que recai sobre coisa própria", (SCAVONE JUNIOR, 2015, p. 523).

Ademais, referido instituto depende de contrato formal, e para que seus efeitos sejam surtidos, é imprescindível que seja registrado na matrícula do imóvel, pois trata-se de direito real de garantia e, portanto, oponível a terceiros. A inovação neste sentido, está relacionada a desnecessidade de escritura pública, pois conforme artigo 38 da Lei 9.514/97, os contratos poderão ser celebrados por "instrumento particular com efeitos de escritura pública".

Ainda, para que seja garantida a eficácia dos contratos, necessário que neles constem: I. O valor da dívida; II. O prazo e as condições de reposição do empréstimo ou do crédito do fiduciário; III. A taxa de juros e os encargos incidentes; IV. A descrição do imóvel objeto da alienação fiduciária (ou o número da matrícula, por analogia ao art. $2^{\circ}$ da Lei 7.433/1985) e a indicação do título e modo de aquisição; V. A cláusula assegurando ao fiduciante, enquanto adimplente, a livre utilização, por sua conta e risco, do imóvel objeto da alienação fiduciária; VI. A indicação, para efeito de venda em público leilão, do valor do imóvel e dos critérios para a respectiva revisão; VII. A cláusula dispondo sobre os procedimentos de que trata o art. 27 (de consolidação da propriedade em caso de inadimplemento).

\subsection{Da Consolidação da Propriedade}

Conforme dispõe o artigo 26, da lei 9.514/97, "vencida e não paga, no todo ou em parte, a dívida e constituído em mora o fiduciante, consolidar-se-á, nos termos deste artigo, a propriedade do imóvel em nome do fiduciário".

Em outras palavras, estando o fiduciante inadimplente, o credor resolverá o contrato, de modo que será descaracterizada a propriedade fiduciária, consolidando-se a propriedade plena em seu favor, haja vista o incumprimento da condição resolutiva pelo devedor.

Ressalta-se que todo o procedimento aqui previsto, será promovido administrativamente pelo credor fiduciário, isto é, não dependerá de apreciação judicial para que seja satisfeita a obrigação a partir da consolidação da propriedade do imóvel:

O que a lei objetivou ao fixar determinado tipo de execução extrajudicial foi, ao lado da sólida garantia que a propriedade fiduciária propicia, tentar afastar os entraves que a demora da prestação jurisdicional opõe ao direito do credor. (BEZERRA FILHO, 2004, p. 124).

No mais, para que seja efetivada a consolidação da propriedade, o devedor deverá, primeiro, ser constituído em mora mediante a notificação - a ser expedida pelo oficial do competente Registro de Imóveis - a qual requererá a satisfação do débito no prazo de 15 (quinze) dias, inclusive das prestações que vencerem até 
a data do pagamento, bem como juros, tributos e demais despesas, sob pena de resolução do contrato.

A notificação deverá ser feita pessoalmente, na presença do devedor ou de seu representante (sob pena de nulidade), e havendo suspeita de ocultação pelo oficial de registro de imóveis ou de registro de títulos, caberá a notificação com hora certa, aplicando-se subsidiariamente o disposto no Código de Processo Civil, nos artigos 252 a 254, admitindo-se também a intimação por edital, nos termos do $\S 4^{\circ}$ do artigo 26.

Transcorrido o prazo de 15 (quinze) dias (ou de quarenta e cinco dias, no caso do art. 26-A), e não purgada a mora, o oficial do Registro de Imóveis, mediante o pagamento do imposto de transmissão (ITBI) pelo fiduciário, promoverá a averbação na matrícula do imóvel da consolidação da propriedade.

Consolidada a propriedade, o fiduciário promoverá o leilão extrajudicial do imóvel, vide artigo 27. No primeiro leilão, só será realizada a arrematação por lance igual ou superior ao valor de avaliação do imóvel; não arrematado o bem, em até 15 (quinze) dias proceder-se-á ao segundo leilão, sendo aceito lance igual ou superior ao valor da dívida (com juros, correção e demais despesas); em caso de necessidade de terceiro leilão, "considerar-se-á extinta a dívida”, vide §5 , art. 27.

As datas, horários e locais dos dois primeiros leilões deverão ser comunicadas ao devedor, que terá direito de preferência na arrematação do bem por preço correspondente ao valor da dívida somada às demais despesas. Caso não exerça tal direito, mas sendo efetivada a venda do imóvel a terceiro, o credor fiduciário terá 05 (cinco) dias para entregar o valor que sobejar ao devedor.

No entanto, a partir do terceiro leilão, como mencionado anteriormente, a dívida será considerada extinta, de modo que, em caso de arrematação por valor superior ao da dívida, nada será devido ao devedor. De igual forma, sendo arrematado o bem por valor inferior ao quantum devido, o credor suportará o prejuízo.

Ressalta-se que tal previsão é objeto de grande discussão no meio jurídico, haja vista estar em desconformidade com a vedação legal quanto ao enriquecimento ilícito do credor (art. 884, do Código Civil), no caso de a venda do imóvel ocorrer por montante superior ao valor do débito.

De fato, o $\S 5^{\circ}$, art. 27, da Lei 9.514/97 não dispõe explicitamente que a restituição da diferença entre o valor da dívida e o valor da arrematação não seja devida a partir do terceiro leilão. No entanto, sua interpretação juntamente com o $\S 4^{\circ}$ do mesmo dispositivo, nos leva a concluir que o objetivo do legislador era exatamente este: extinguir as obrigações para ambas as partes, sendo a venda efetivada ou não, e sendo o valor de arrematação suficiente ou não, após o segundo leilão negativo. Senão vejamos o que dispõe os parágrafos do aludido artigo:

$\S 4^{\circ}$ Nos cinco dias que se seguirem à venda do imóvel no leilão, o credor entregará ao devedor a importância que sobejar, considerando-se nela compreendido o valor da indenização de benfeitorias, depois de deduzidos os valores da dívida e das despesas e encargos de que tratam os $\S \S 2^{\circ}$ e $3^{\circ}$, fato esse que importará em recíproca quitação [...]. 
$\S 5^{\circ}$ Se, no segundo leilão, o maior lance oferecido não for igual ou superior ao valor referido no $\S 2^{\circ}$, considerar-se-á extinta a dívida e exonerado o credor da obrigação de que trata o $§ 4^{\circ}$. (BRASIL, Lei 9.514, 1997).

Portanto, imagine a seguinte situação hipotética: o fiduciante transfere a propriedade resolúvel de imóvel específico ao fiduciário, em troca de crédito, de modo que se obriga a pagar as prestações e, ao final destas, seu domínio sob o imóvel volta ao status quo. Para fins de exemplificação, desconsideremos os juros e correção, levando em conta que a dívida total corresponde ao valor de $\mathrm{R} \$ 500.000,00$ (quinhentos mil reais), e o imóvel deixado em garantia, corresponde ao valor de $\mathrm{R} \$$ 600.000,00 (seiscentos mil reais).

Neste caso, após o adimplemento da metade do contrato, o fiduciante incorre ao inadimplemento das demais parcelas, constituindo um débito de $\mathrm{R} \$ 250.000,00$ (duzentos e cinquenta mil reais), de modo que o fiduciário, na forma prevista em lei, procede com a consolidação da propriedade do imóvel deixado em garantia.

Consolidada a propriedade, o fiduciário promove o primeiro leilão, com lance mínimo de $\mathrm{R} \$ 600.000,00$ (seiscentos mil reais), não logrando êxito. No segundo leilão, com lance mínimo de $\mathrm{R} \$ 400.000,00$ (quatrocentos mil reais), também restando negativo. No terceiro leilão, porém, efetiva-se a venda do imóvel pelo valor de $\mathrm{R} \$ 300.000,00$ (trezentos mil reais). Veja que, neste caso, conforme inteligência do art. $27, \S 5^{\circ}$, o devedor fiduciante não terá direito a restituição da diferença entre o valor da arrematação e o valor do débito, correspondente a $\mathrm{R} \$ 50.000$,00 (cinquenta mil reais), visto que a venda foi realizada apenas na terceira praça.

Muitos autores, inclusive, entendem que tal questão deriva de grande falha na legislação, a qual permite ao fiduciário uma altíssima lucratividade em detrimento de onerosidade excessiva do devedor. Os devedores que passam por esta experiência, muitas vezes ingressam com ação judicial para que tal preceito seja revisto, e então, nos deparamos com diversas decisões controvertidas, ocasionando na insegurança jurídica do assunto.

\section{O ADIMPLEMENTO SUBSTANCIAL E SUA APLICAÇÃO NA ALIENAÇÃO FIDUCIÁRIA DE IMÓVEL}

A teoria do adimplemento substancial, como tese limitadora do direito potestativo do credor (previsto no artigo 475 do Código Civil), tem sido muito utilizada pelos intérpretes ativistas, que entendem não ser plausível a resolução do contrato em detrimento de inadimplemento insignificante da obrigação. Esta teoria, ainda, apesar de não prevista legalmente, é fundamentada nos princípios da boa-fé objetiva, bem como na função social do contrato.

Dito isto, e sendo esta tese amplamente recepcionada pelos princípios e objetivos constitucionais, sua aplicação não poderia, portanto, ser afastada dos negócios fiduciários existentes, principalmente pelo fato de que, tais negócios jurídicos comumente são dotados de abuso por parte dos credores.

No entanto, apesar do crescente número de decisões favoráveis à sua aplicação em aludidos casos, em 2017, o Superior Tribunal de Justiça entendeu pela 
inaplicabilidade do adimplemento substancial nos casos de alienação fiduciária, haja vista tratar-se de procedimento regulamentado em legislação especial, não cabendo, portanto, a intervenção judicial embasada em regras gerais, o que gerou grande influência nos demais tribunais.

Com a devida vênia, entendemos não ser este o melhor posicionamento a ser adotado, uma vez que o procedimento previsto na lei de alienação fiduciária de imóvel é propenso a demasiadas desproporcionalidades e injustiças, que apresentam flagrante desconformidade para com os princípios constitucionais. No entanto, dada a realidade de nosso sistema jurídico, que apesar de neoconstitucionalista, conserva sua tradição romano-germânica, não podemos reduzir a solução do problema simplesmente à defesa de decisões contrárias ao STJ, principalmente pelo fato da insegurança jurídica, que não seria suprida. O que defendemos, na realidade, é a normatização da teoria do adimplemento substancial na Lei 9.514/97.

Veja que, o ativismo judicial já cumpriu com seu papel na inclusão de referida tese nas pautas de nosso ordenamento, demonstrando assim os novos anseios da sociedade nas relações jurídicas atuais. No entanto, é necessário que o legislativo cumpra também com sua função, na regularização de matéria que carece de previsão.

Ressalta-se, ainda, que quando tratamos de abuso de direito e enriquecimento ilícito - práticas defesas em lei - no âmbito da Lei 9.514/97, tratamos de situações extremamente delicadas, das quais resultam em flagrantes injustiças contra o devedor fiduciante.

Tais práticas ilícitas estão comumente presentes nos negócios fiduciários imobiliários, justamente pela extrajudicialidade atribuída ao procedimento executório nos casos de inadimplemento.

O que ocorre é que, objetivando estimular o mercado, referido instituto (alienação fiduciária de imóvel) careceu de dispositivos que limitassem a atuação dos credores fiduciários que, muitas vezes, incorrem no abuso de direito e enriquecimento sem causa por meio de práticas que, embora legítimas do ponto de vista legal (dada a existência de legislação específica), mostram-se completamente desproporcionais e contrárias a preceitos constitucionais. Sem a apreciação do Judiciário, o controle fica inteiramente nas mãos do credor, que se torna "o próprio juiz" de sua própria causa.

O autor Manoel Justino Bezerra Filho, crítico do procedimento de consolidação da propriedade previsto na Lei 9514/97, discorre em sua obra:

A par de arrostar princípios doutrinários e jurisprudenciais já solidificados, de investir contra a consciência de proteção do mais fraco que já permeia o direito ocidental desde fins do Século XIX, de afrontar diretamente diversos artigos do Código de Defesa do Consumidor, de desconsiderar sumariamente postulados constitucionais de natureza positiva, é ainda lei que traz uma "pena" desproporcional ao "delito", que estabelece uma sanção que pode fazer com que se chegue ao objetivo pretendido - ou seja, fluxo de capitais suficiente para o financiamento imobiliário ante a facilitação da cobrança do débito pelo investidor -, mas que, certamente, ao invés de usar do meio menos gravoso, lança 
mão de meio que mais que gravoso, adentra as fronteiras da iniquidade. (BEZERRA FILHO, 2004, p. 171).

Neste sentido, e a partir de todo o estudo realizado quanto ao sistema jurídico brasileiro, à teoria do adimplemento substancial e à alienação fiduciária de imóvel, com a devida vênia, compartilhamos do posicionamento do autor. Em que pese a importância do negócio fiduciário imobiliário para a economia nacional, é necessário que seja alcançada a equidade entre as partes contratantes. A onerosidade excessiva para o devedor fiduciante confronta os princípios do Estado brasileiro.

Entretanto, a dependência de interpretação ativista - de acordo com valores pessoais de cada intérprete do direito - para que eventuais desproporcionalidades sejam evitadas, é o mesmo que abdicar da tradição romano-germânica de nosso sistema, e negar a primazia da lei em nosso ordenamento jurídico, o que não é o caso.

Abboud e Mendes criticam severamente o ativismo judicial que permeia pelo Judiciário; para estes autores, "Juízes não são, diretamente, agentes de transformação da realidade. Juízes são protetores do direito, [...]. Juízes asseguram as regras do jogo e a estabilidade democrática, para assim possibilitar que a transformação da realidade opere nas instâncias adequadas" (2019, p. 6), grifo nosso.

Portanto, temos que direito contemporâneo visa, sim, a efetividade de princípios e objetivos constitucionais; no entanto, esta efetividade deve ser garantida mediante norma, isto é, fonte de direitos compatível com nosso sistema jurídico, qual seja, civil law. Não se atingirá a segurança jurídica e a justiça plena, mediante direitos incertos.

Por esta razão, enfim, entendemos ser a normatização do adimplemento substancial essencial em nosso ordenamento jurídico; e para que seja garantida sua eficácia na alienação fiduciária de imóvel, que tal norma seja taxativa e inclusa na Lei 9.514/97, dispondo inclusive sobre os critérios de aplicação, para que não haja lacuna neste sentido. Só assim se vislumbra a resolução da problemática neste trabalho abordada.

\section{CONSIDERAÇÕES FINAIS}

Conforme exposto, a teoria do adimplemento substancial, no âmbito jurídico nacional, é uma construção doutrinária e jurisprudencial que consiste, em suma, na não resolução do contrato em decorrência de inadimplemento ínfimo, e baseia-se no princípio da boa-fé contratual e da função social do contrato.

O enfoque deste trabalho, está na aplicação desta teoria nos casos de consolidação da propriedade, provenientes de contratos de alienação fiduciária de imóvel. Nestas situações, a abusividade dos credores fiduciários gera a necessidade de ponderação do procedimento administrativo previsto na Lei 9.514/97, sendo que a doutrina do adimplemento substancial preencheria a lacuna deixada pela legislação.

No entanto, o problema está na insegurança jurídica que incide sobre referida teoria, insegurança essa, que ainda se agrava pelo fato de que, a alienação fiduciária de imóvel está prevista em legislação especial, o que possibilita linhas interpretativas contrárias à aplicação do inadimplemento mínimo nestes casos. 
Portanto, de um lado, temos um procedimento que carece de ponderação, e de outro, temos uma teoria que preencheria esta necessidade. A questão está na insegurança jurídica: decisões ativistas são discricionárias, não garantindo a certeza do direito. Assim, haja vista não estar o adimplemento substancial previsto em lei, sua aplicação é dependente da discricionariedade do intérprete ativista, o que ocasiona no chamado anarquismo judicial, onde não se sabe o que esperar das demandas judiciais.

Como consequência desta insegurança jurídica, temos, por exemplo, a injustiça decorrente do desfecho diferente entre casos análogos, mas julgados por magistrados distintos. Ou, temos também a perpetuação dos abusos dos credores que, cientes da grande possibilidade de impunidade, continuam obtendo vantagens desproporcionais dos devedores de boa-fé.

A partir do estudo de ambos os institutos, portanto, foi possível confirmar a hipótese inicialmente levantada, e concluir que a normatização do adimplemento substancial na Lei 9.514/97 solucionaria o problema.

Constatou-se ainda que, o critério quantitativo para que o adimplemento substancial seja configurado, é a melhor opção nos casos de negócio fiduciário imobiliário, visto que as obrigações atribuídas ao devedor são pecuniárias, não havendo margem para análise qualitativa.

Além disso, a partir das pesquisas realizadas, também foi possível detectar a preocupação dos intérpretes contrários à aplicação do adimplemento substancial na alienação fiduciária de imóvel: temem o prejuízo das instituições financeiras - $\mathrm{o}$ que interferiria na economia do país - e o abuso por parte dos devedores, que cientes do afrouxamento do procedimento previsto na Lei 9.514/97, podem, de má-fé, inadimplir as últimas prestações.

Por isso, seria de suma importância a adoção de critério social para o reconhecimento do adimplemento substancial das prestações advindas do negócio fiduciário, e consequente impedimento à consolidação da propriedade: a inexistência de outro imóvel no patrimônio do devedor. Desta feita, a aplicação do adimplemento substancial nos casos de alienação fiduciária de imóvel estaria restrita às situações de ameaça ao direito fundamental de moradia, conferido pelo artigo $6^{\circ}$, CF/ 88.

\section{REFERENCIAS}

ABBOUD, Georges; e MENDES, Gilmar Ferreira. Ativismo Judicial: Notas Introdutórias a uma Polêmica Contemporânea. Revista dos Tribunais Online, volume 1008, 2019.

ALEMANHA. Código Civil. Acesso em: 15/05/2020. Disponível em: https:/ /www.gesetze-im-internet.de/bgb/_323.html.

ALVIM, Arruda. Alienação fiduciária de bem imóvel. O contexto da inserção do instituto em nosso direito e em nossa conjuntura econômica. Revista de Direito Privado, n. 2, 2000. 
BARROSO, Luís Roberto. Judicialização, Ativismo Judicial e Legitimidade Democrática. Migalhas, 2009. Acesso em 09/04/2020. Disponível em: https:/ /www.migalhas.com.br / arquivo_artigo/art20090130-01.pdf.

BECKER, Anelise. A doutrina do adimplemento substancial no Direito brasileiro e em perspectiva comparativista. Porto Alegre: Revista da Faculdade de Direito UFRGS, 1993.

BEZERRA FILHO, Manoel Justino. A EXECUÇÃO EXTRAJUDICIAL DO CONTRATO DE ALIENAÇÃO FIDUCIÁRIA DE BEM IMÓVEL - EXAME CRÍTICO DA LEI 9.514, DE 20.11.97. Artigo publicado na Revista dos Tribunais no 819, de janeiro de 2004.

BRASIL, Decreto-Lei 911. Altera a redação do art. 66, da Lei $n^{\circ} 4.728$, de 14 de julho de 1965, estabelece normas de processo sobre alienação fiduciária e dá outras providências. 1969. Acesso em: 29/05/2020. Disponível em: http://www.planalto.gov.br/ccivil_03/decreto-lei/1965-1988/del0911.htm.

BRASIL, Constituição da República Federativa do Brasil. 1988. Acesso em: 29/05/2020. Disponível em: http://www.planalto.gov.br/ccivil_03/constituicao/ constituicao.htm.

BRASIL, Código de Defesa do Consumidor. 1990. Acesso em: 29/05/2020. Disponível em: http:/ / www.planalto.gov.br/ccivil_03/leis/18078.htm.

BRASIL, Lei 9.514. Dispõe sobre o Sistema de Financiamento Imobiliário, institui a alienação fiduciária de coisa imóvel e dá outras providências. 1997. Acesso em: 29/05/2020. Disponível em: http://www.planalto.gov.br/ccivil_03/leis/19514.htm.

BRASIL, Código Civil. 2002. Acesso em: 29/05/2020. Disponível em: http:/ / www.planalto.gov.br/ccivil_03/leis/2002/110406.htm.

BRASIL, Código de Processo Civil. 2015. Acesso em: 29/05/2020. Disponível em: http:/ / www.planalto.gov.br/ccivil_03/_ato2015-2018/2015/lei/113105.htm.

BUSSATTA, Eduardo Luiz. Resolução dos Contratos e Teoria do Adimplemento Substancial. São Paulo: Saraiva, 2007.

COUTO E SILVA, Clóvis Veríssimo do. O Princípio da Boa Fé no Direito Brasileiro e Português, in Estudos de Direito Civil Brasileiro e Português. São Paulo: Revista dos Tribunais, 1980.

COUTO E SILVA, Carlos Veríssimo. A obrigação como processo. 01 a Edição. Rio de Janeiro: Editora FGV, 2006. 
COUTO E SILVA, Carlos Veríssimo. Estudos de direito civil brasileiro e português: I Jornada luso-brasileira de direito civil". São Paulo: Revista dos Tribunais, 1980.

DWORKIN, Ronald. Levando os direitos a sério. Tradução Jefferson Luiz Camargo. $2^{\circ}$ Edição. São Paulo: Martins Fontes, 2007.

FABRÍCIO, Adroaldo Furtado. Alienação fiduciária de imóveis segundo a lei no 9.514/97. Revista da AJURIS, n. 80, 2000.

FERREIRA, Antônio Carlos. A interpretação da doutrina do adimplemento substancial. CONJUR. Acesso em: 25/05/2020. Disponível em: https://www.conjur. com.br/ 2015-fev-09/ direito-civil-atual-interpretacao-doutrina-adimplemento-substanci al-parte.

FRADERA, Vera Jacob de. A contribuição de Ruy Rosado de Aguiar Jr: o doutrinador (parte III). Revista Consultor Jurídico, 2019. Acesso em: 15/05/2020. Disponível em: https:/ / www.conjur.com.br/2019-dez-23/direito-civil-atual-contribuicao-ruy-rosado-aguiar-jr-doutrinador-parte-iii.

GICO JUNIOR, Ivo Teixeira. Anarquismo Judicial e Segurança Jurídica. Revista Brasileira de Políticas Públicas, volume 5, 2015.

GONÇALVES, Carlos Roberto. Direito Civil Brasileiro: Parte Geral. $13^{\circ}$ Edição. São Paulo: Saraiva, 2015.

GONÇALVES, Carlos Roberto. Direito Civil Brasileiro - Direito das Coisas. $15^{\text {a }}$ Edição. São Paulo: Saraiva Educação, 2020.

ITÁLIA. Código Civil. Acesso em: 15/05/2020. Disponível em: http:/ /www.rcscuola.it/ disciplina/ ccivile.pdf.

PORTUGAL. Código Civil. Acesso em: 15/05/2020. Disponível em: http:/ /www.pgdlisboa.pt/leis/lei_mostra_articulado.php?ficha=701\&artigo_id=\&nid=775\&pagina=8\&tabela $=$ leis\&nversao $=\&$ so_miolo $=$.

ROSSI, Amélia Sampaio; e PAMPLONA, Danielle Anne. Neoconstitucionalismo e Ativismo Judicial: Democracia e Constitucionalismo em Oposição ou Tensão Produtiva. Revista do Programa de Pós-Graduação em Direito da UFC, volume 33.2, 2013.

SCAVONE JUNIOR, Luiz Antônio. Direito Imobiliário: Teoria e Prática. 09ª Edição. Rio de Janeiro: Forense, 2015. 
SIQUEIRA, Mariana Ribeiro. O adimplemento substancial e a vedação ao direito abusivo de resolução contratual em instrumentos dotados de cláusula resolutiva expressa. In: TEPEDINO, Gustavo; OLIVA, Milena Donato (Coord.). Teoria do Direito Civil: questões controvertidas. Belo Horizonte: Fórum, 2019, p. 311-335.

STRECK, Lenio Luiz. Jurisdição Constitucional. 5a Edição. Rio de Janeiro: Forense, 2018. Acesso em 22/04/2020. Disponível em: https://forumdeconcursos.com/wp-content/ uploads/ wpforo/attachments/2/1686-Jurisdio-Constitucional-Lenio-Luiz-Streck-2018. pdf.

TARTUCE, Flávio. A função social dos contratos: do Código de Defesa do Consumidor ao novo Código Civil. São Paulo: Método, 2005.

TEPEDINO, Gustavo. Normas Constitucionais e Relações Privadas na Experiência das Cortes Superiores Brasileiras. Brasília: Revista do Tribunal Superior do Trabalho, volume $77, \mathrm{n}^{\mathrm{o}} 3,2011$.

TEPEDINO, Gustavo. Ativismo Judicial e Construção do Direito Civil: Entre Dogmática e Práxis. Revista Novos Estudos Jurídicos - Eletrônica, volume 24, nº 1, 2019.

VENOSA, Sílvio Salvo. Direito civil. vol.1. São Paulo: Editora Atlas, 2003. 